\title{
Bepotastine besilate ophthalmic solution I.5\% for alleviating nasal symptoms in patients with allergic conjunctivitis
}

This article was published in the following Dove Press journal:

Journal of Asthma and Allergy

\section{Megan E Cavet' \\ Paul J Gomes ${ }^{2}$ \\ Warner W Carr ${ }^{3}$ \\ Jon I Williams ${ }^{4}$}

'Bausch + Lomb, Rochester, NY, ${ }^{2}$ Ora, Andover, MA, ${ }^{3}$ Allergy and Asthma Associates of Southern California, Mission Viejo, CA, ${ }^{4}$ Bausch + Lomb, Irvine, CA, USA
Correspondence: Megan E Cavet Bausch + Lomb, 1400 North Goodman Street, Rochester, NY 14609, USA Email megan.cavet@bausch.com
Background: Bepotastine besilate ophthalmic solution (BBOS) $1.5 \%$ is a topical antihistamine for the treatment of ocular itching associated with allergic conjunctivitis (AC). Allergic rhinitis and $\mathrm{AC}$ are common comorbid conditions. We explored the efficacy of BBOS $1.5 \%$ in alleviating nasal symptoms in an integrated analysis of two Phase III conjunctival allergen challenge (CAC) studies and a Phase IV environmental allergen study.

Methods: In the Phase III trials, a CAC was performed 15 minutes, 8 hours, and 16 hours following ocular instillation of BBOS $1.5 \%(n=78)$ or placebo $(n=79)$, and subjects evaluated nasal symptoms. In the environmental study, subjects instilled BBOS $1.5 \%(n=123)$ or placebo $(\mathrm{n}=122)$ twice daily and nasal symptoms were evaluated over 2 weeks.

Results: In the Phase III trials, BBOS $1.5 \%$ had reduced CAC-induced nasal congestion and pruritus at 15 minutes and 8 hours postdosing and rhinorrhea and a non-ocular compositesymptom score (sum of nasal scores plus ear or palate pruritus) at all time points postdosing (all $P \leq 0.01$ vs placebo). In the Phase IV environmental study, BBOS $1.5 \%$ reduced sneezing and nasal pruritus over 2 weeks and median number of days to improvement of nasal pruritus and total nasal symptom score (sum for rhinorrhea, sneezing, nasal pruritus, and nasal congestion; $P \leq 0.04$ vs placebo). Additionally, investigator-reported improvement in overall ocular (pruritus, hyperemia, tearing) and nasal symptoms was greater with BBOS $1.5 \%$ vs placebo $(P \leq 0.03)$.

Conclusion: Results of these exploratory analyses indicate that topical ocular BBOS 1.5\% reduced nasal symptoms, supporting its use for alleviating rhinitis symptoms associated with AC. Keywords: bepotastine besilate, nasal symptoms, allergic rhinitis, conjunctivitis, conjunctival allergen challenge, antihistamine

\section{Introduction}

Allergic conjunctivitis (AC) and allergic rhinitis (AR) are the most common allergic diseases, and symptoms of both conditions coexist in more than $80 \%$ of allergic patients. ${ }^{1}$ Increasing prevalence of $\mathrm{AC}$ and $\mathrm{AR}$ has been reported over the past 20 years. Comorbid AC and AR is estimated to affect $9 \%-40 \%$ of the US population, a figure that may fall short of the true prevalence, as many patients self-manage their

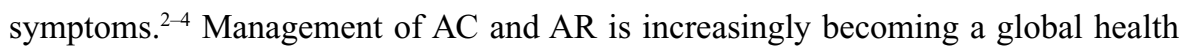
problem, due to its impact on patient quality of life, performance, and productivity. ${ }^{1,3}$

The eye and nose are particularly prone to allergic response, because their mucosal surfaces are directly exposed to environmental allergens. In susceptible individuals, repeated allergen exposure triggers a type I hypersensitivity cascade at the ocular surface and nasal cavity, causing mast-cell degranulation and histamine release. Histamine 
is responsible for the early phase of the allergic response, characterized by the classic symptoms of ocular and nasal pruritus, conjunctival hyperemia (redness), tearing, sneezing, and rhinorrhea. ${ }^{1,5,6}$ Some 6-24 hours later, eosinophils and other inflammatory cells infiltrate the conjunctival and nasal mucosa, causing eyelid swelling, further ocular hyperemia, congestion, sneezing, and rhinorrhea. ${ }^{1,5,6}$

Pharmacological therapies for the relief of signs and symptoms of AC and AR include dual-acting second-generation antihistamine/mast-cell stabilizers, first-generation antihistamines/vasoconstrictors, first-generation antihistamines, mast-cell stabilizers, nonsteroidal anti-inflammatory drugs (NSAIDs), and corticosteroids. ${ }^{5,7}$ Similarities between the allergic responses in the conjunctiva and nasal mucosa and commonality among pharmacological agents used to treat allergy responses in both of these tissue types suggest that eyedrops might alleviate both nasal and ocular allergic symptoms. ${ }^{6,8}$ Further, topically applied ophthalmic medications may be efficacious in the treatment of concurrent nasal symptoms, likely because a significant proportion of the drug is expected to reach the nasal mucosa via the nasolacrimal duct. ${ }^{1,8}$

Bepotastine besilate (BB) is a second-generation, dual-mechanism drug possessing highly selective direct histamine $\mathrm{H}_{1}$-receptor-antagonistic action and inhibitory effects on histamine release from mast cells. BB also acts to suppress eosinophilic migration into inflammatory sites, and at a molecular level can potentially inhibit the activation of eosinophils and maturation of eosinophil precursors in allergic inflammation. ${ }^{9}$ In 2000 , BB (Talion ${ }^{\circledR}$ tablets; Ube Industries Tokyo, Japan) was approved in Japan as an oral treatment for AR, and an indication of pruritus associated with urticaria and other skin diseases was added in 2002.9,10 A topical ophthalmic formulation ( bepotastine besilate ophthalmic solution [BBOS] 1.5\%; Bepreve ${ }^{\circledR}$; Bausch \& Lomb Incorporated, Bridgewater, NJ, USA) was approved by the US Food and Drug Administration (FDA) in 2009 for the treatment of pruritus associated with AC, with twice-daily dosing in patients aged $\geq 2$ years. ${ }^{9}$

Therapeutic efficacy and safety of topical BBOS $1.5 \%$ for the treatment of signs and symptoms of AC was demonstrated in two Phase III randomized placebo-controlled US clinical studies using the conjunctival allergen challenge (CAC) clinical model. ${ }^{11,12}$ This model simulates ocular allergic response in a standardized and reproducible manner, and has been validated in a number of previous studies. ${ }^{13-18}$ Notably, CAC studies are conducted only in patients who do not have active $\mathrm{AC}$, and thus confounding variables, such as fluctuation in environmental pollen counts and exposure, are minimized. ${ }^{17}$
The Phase III studies demonstrated that BBOS $1.5 \%$ alleviated allergen-induced ocular pruritus whether the CAC was administered 15 minutes or 8 hours after drug instillation. Also, conjunctival hyperemia was significantly reduced at all time points when the CAC was administered 15 minutes after BBOS $1.5 \%$ instillation. Reduction in ocular symptoms occurred at the first time point assessed after administration of the CAC, namely 3 minutes for pruritus and 7 minutes for hyperemia. ${ }^{11,12}$

The efficacy and safety of BBOS $1.5 \%$ for signs and symptoms of AC were further evaluated in a Phase IV environmental allergen-exposure study. Subjects were randomized to BBOS $1.5 \%$ or placebo instilled bilaterally twice daily for 14 days. Treatment with BBOS $1.5 \%$ significantly reduced ocular pruritus compared with vehicle over the 2-week study period in subjects with a history of seasonal allergies. ${ }^{19}$

Ocular instillation of BBOS $1.5 \%$ may relieve nasal pruritus and other nasal symptoms associated with AR. Indeed, BBOS $1.5 \%$ has previously been reported to reduce CACinduced nonocular symptoms of rhinorrhea, nasal congestion, and nasal pruritus for one Phase III CAC trial. ${ }^{6}$ Further, a randomized, observer-masked, single-center crossover study in 30 subjects with AC accompanied by nasal symptoms evaluated the subject-perceived relief of ocular itch and nasal symptoms with BBOS $1.5 \%$ and the antihistamine olopatadine hydrochloride $0.2 \%$. A significantly greater proportion of these subjects preferred BBOS $1.5 \%$ over olopatadine hydrochloride $0.2 \%$ for relief of ocular itching, and also for relief of nasal pruritus/rhinorrhea. ${ }^{20}$

Results for ocular end points with BBOS $1.5 \%$ integrated across the two pivotal Phase III CAC trials ${ }^{21}$ and from the environmental allergen Phase IV study ${ }^{19}$ have been reported previously. Here, we report on secondary efficacy end points related to nasal symptoms from these studies, with the aim of expanding the evidence base for considering BBOS $1.5 \%$ as an ocular drug that alleviates both ocular and comorbid nasal symptoms. ${ }^{7}$

\section{Methods}

Data in these analyses were extracted from three previously conducted studies ${ }^{11,12,21}$ evaluating the efficacy and safety of BBOS $1.5 \%$ in the treatment of AC. These included two Phase III randomized double-masked placebo-controlled CAC clinical trials (one single-center study [NCT00424398] and one multicenter study [NCT00586664]) in subjects with AC with or without nasal symptoms, and a Phase IV randomized double-masked placebo-controlled multi-center environmental allergen study (NCT01174823) in subjects with seasonal $\mathrm{AC}$ associated with nasal allergy symptoms. Subjects were 
enrolled from March to April 2007 for the single-site study, from November 2007 to March 2008 for the multi-site study, and from July to October 2010 for the Phase IV study. Efficacy end points related to resolution of ocular signs and symptoms of AC have been reported previously. ${ }^{11,12,19,21}$ Here we report and compare $\mathrm{CAC}$ and environmental results for secondary efficacy outcomes related to nasal symptoms in subjects with AC and comorbid nasal symptoms.

All three trials were approved by independent institutional review boards ( single-center CAC, IntegReview, Austin, TX; multi-center CAC, Coast IRB, Colorado Springs, CO; environmental allergen study, Quorum Review IRB, Seattle, WA) and conducted in accordance with the International Conference on Harmonisation Good Clinical Practice guidelines and the Declaration of Helsinki. Written informed consent was obtained from all participants or their parent/legal guardian, and with informed assent from participants as applicable.

\section{Phase III CAC studies Design}

Details of study design, subject inclusion/exclusion criteria, and ocular and nonocular efficacy end points for the Phase III CAC studies have been described elsewher. ${ }^{6,11,12,21}$ In brief, male and female subjects $\geq 10$ years of age diagnosed with AC were eligible to participate if they had elicited a positive skin-test reaction to at least one relevant seasonal or perennial allergen (cat hair, cat dander, grasses, ragweed, and/or trees) within the prior 24 months. The trial design is shown in Figure 1. During the screening period, at visit 1 (day $-21 \pm 3$ ), subject-specific allergen titration was performed to identify the lowest concentration of allergen to elicit a robust ocular allergic response, defined as a positive bilateral CAC reaction score $\geq 2$ in ocular pruritus and $\geq 2$ in ocular redness in two of three predefined vessel beds within 10 minutes of the CAC. To establish reproducibility, the allergic response of the subject to the lowest allergen concentration identified was confirmed with a repeat CAC at visit 2 (day $-14 \pm 3$ ).

Following the screening period, eligible subjects were randomized to treatment and completed three CAC visits. At these visits, subjects received a single drop of their assigned treatment (BBOS $1.5 \%$, BBOS $1 \%$, or placebo [vehicle] bilaterally) and completed a CAC thereafter. Visit 3 (day 1) and visit 4 (day 14 \pm 3 ) CACs were administered 16 hours and 8 hours after treatment instillation, respectively, and were intended to determine the duration of action of BBOS,

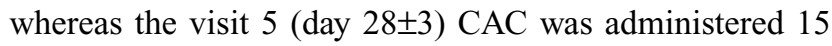
minutes after treatment instillation and was intended to determine the onset of action of BBOS. Only the outcomes for the $1.5 \%$ dose of BBOS, which is the marketed dose, are presented here.

\section{Outcome measures}

Nasal symptoms assessed as secondary end points were rhinorrhea, nasal congestion, nasal pruritus, and a nonocular composite symptom (NOCS) score (comprised of the these three symptoms plus ear or palate pruritus). Each end point was scored at 7, 15, and 20 minutes after each CAC by each subject using previously established grading scales. ${ }^{17,22}$ Nasal congestion, rhinorrhea, nasal pruritus, and ear or palate pruritus were each graded on a scale of $0-4$ (0 none, 1 mild,

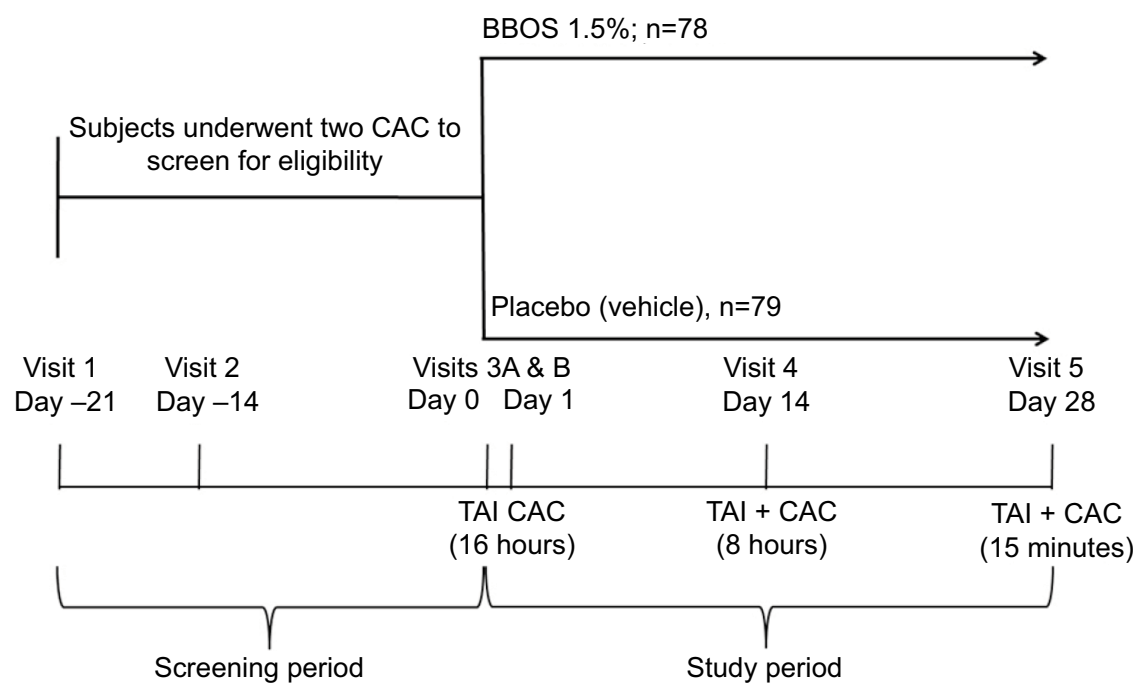

Figure I Phase III conjunctival allergen challenge (CAC) study design.

Notes: CACs were administered 15 minutes (onset of action), 16 hours and 8 hours (duration of action) after treatment instillation and nasal symptoms were measured at 7, 15, and 20 minutes post-CAC. The study also included a BBOS $1 \%$ arm, the results of which are not reported here.

Abbreviations: BBOS, bepotastine besilate ophthalmic solution; TAl, test-agent instillation. 
2 moderate, 3 moderate/severe, 4 severe, whole-unit increments). NOCS score was thus calculated on a scale of $0-16$.

\section{Statistical analysis}

Nasal symptom scores (NSSs) were pooled across the two Phase III CAC studies and analyzed for the intent-to-treat population using the last observation carried forward. Differences in mean NSSs between placebo and BBOS 1.5\% were evaluated using parametric two-sided statistical $t$-tests. The analysis utilized the same testing procedure as that utilized for the primary ocular end points in the CAC studies, with Bonferroni correction..$^{6,11,12,21}$ Treatment differences for nasal symptoms were considered statistically significant for the onset-of-action test if $P \leq 0.0125$ and for the duration-ofaction tests if $P \leq 0.00625$ for two or more of the time points at these test visits.

A clinically significant difference in NSSs was defined as at least a 1-unit difference in mean grades (between placebo and BBOS $1.5 \%$ ) at two or more of the time points within a study visit, and at least a 0.5 -unit difference for all time points within a study visit. Treatment differences for NOCS scores were considered statistically significant if $P \leq 0.05$. $P$-values were adjusted for multiple comparisons using the false-discovery rate..$^{6,11,12,21}$

\section{Phase IV environmental allergen study Design}

Details of study design, subject inclusion/exclusion criteria, and primary (ocular) efficacy end points for the Phase IV environmental allergen exposure study have been described elsewhere. ${ }^{19}$ Male and female subjects $\geq 12$ years of age diagnosed with $\mathrm{AC}$ accompanied by rhinitis nasal symptoms ( $\geq 2$-year history) were eligible for study entry if they had had a positive skin-test reaction to at least one relevant seasonal or perennial allergen (cat hair, cat dander, grasses, ragweed, and/or trees) within 1 year of the screening visit. Disallowed medications during the study were any intranasal or ocular medications and oral antihistamines, corticosteroids, and NSAIDs.

The environmental allergen study consisted of four visits (Figure 2). At visit 1 (day -7), eligible subjects were given a diary to record their allergy symptoms twice daily for a week: reflective individual NSS (rINSS; 12 hours since last grading) for nasal pruritus, nasal congestion, rhinorrhea, and sneezing, each on a $0-3$ scale ( 0 none, 1 mild, 2 moderate, 3 severe, whole-unit increments).

Subjects with a reflective total NSS (rTNSS), or the sum of the four rINSS values, of $\geq 7 / 12$ for at least four assessments (morning or evening) on the 7 days prior to visit 2 (day 0), including one assessment at the first visit, were eligible to enroll in the study. At visit 2 (day 0), eligible subjects were randomized to either BBOS $1.5 \%$ or placebo (vehicle) self-instilled twice daily (morning or evening) for 2 weeks.

Subjects self-assessed and recorded their NSSs in their diaries twice daily (morning and evening) just before instillation of the test agent for the 15-minute period before scoring (instantaneous INSS [iINSS]) and for the 12-hour period since the last instillation (rINSS). Subjects were contacted by phone (day $7 \pm 1$, visit 3 ) to monitor compliance and solicit adverse events (AEs). Subjects returned their diaries at visit 4 (day 14 \pm 2 ). Global therapeutic response (overall assessment of nasal symptoms, ocular pruritus, hyperemia, and tearing) was graded by subjects at day 13 and investigators at visit 4 .

\section{Outcome measures}

The primary efficacy end point was change from baseline in subjects' quality of life measured by the Rhinoconjunctivitis Quality of Life Questionnaire - standardized activities at

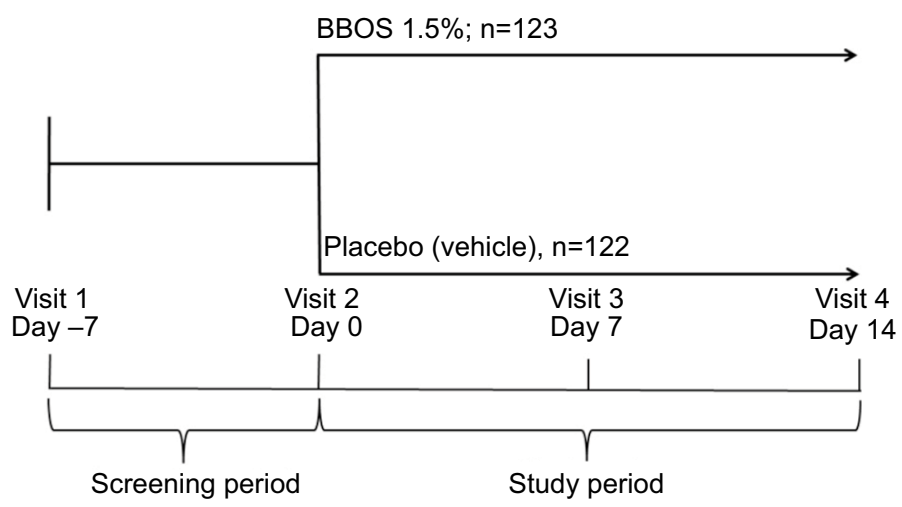

Figure 2 Phase IV environmental allergen study design.

Notes: During the study period, subjects instilled BBOS I.5\% $(n=123)$ or placebo $(n=122)$ and recorded their nasal symptoms twice-daily. At visit 3 (day $7 \pm I)$, subjects were contacted by phone for compliance and adverse-event assessments. Safety assessments were also conducted at visit 4 (day $14 \pm 2$ ).

Abbreviation: BBOS, bepotastine besilate ophthalmic solution. 
the end of 2 weeks of treatment. The focus of this article is the nasal secondary end points, including the mean change from baseline for each of the iINSS and rINSS values (nasal pruritus, nasal congestion, rhinorrhea, and sneezing) and the instantaneous iTNSS (sum of the iINSS) and rTNSS (sum of the rINSS) values over the 2 -week treatment period. The mean change from baseline in the daily averaged scores over the 2 weeks of treatment was also analyzed to explore the effects of BBOS $1.5 \%$ by day and time. The time to onset of relief for each nasal symptom end point (measured as median days to improvement) and the global therapeutic response (scored on a $0-3$ whole-unit scale; 0 no change, 1 slight improvement, 2 improved, 3 marked improvement) was also reported.

\section{Statistical analysis}

All nasal symptom end points were analyzed for the intentto-treat population using the last observation carried forward. For each nasal symptom end point, baseline values were calculated as the averaged responses of the last seven measurements collected twice daily during the screening period (ie, the last 3 days of the screening period and the morning value collected at visit 2 ). The treatment-period mean value was the twice-daily averaged responses collected for all postdosing assessments during the 14-day treatment period. Statistical significance for the difference in mean change from baseline between BBOS 1.5\% and placebo for each nasal symptom (INSS) and for the summed symptoms (TNSS) was determined by analyses of covariance $(P \leq 0.05)$.

The time to onset of improvement for each nasal symptom endpoint was assessed as the first time point of a total of at least three consecutive time points for which there was a greater decrease from baseline in the mean daily averaged twice-daily scores for BBOS $1.5 \%$ vs placebo. Subjects with an improvement from baseline, defined as a $\geq 1$-point reduction for each iINSS or rINSS and $\geq 2$-point reduction for iTNSS or rTNSS values were included in the analysis for each end point. With the exception of the last two scheduled time points, confirmation of improvement for the next two successive time points was required to be considered improvement. Time-to-onset analyses (median days to improvement) were evaluated using log-rank statistics $(P \leq 0.05)$. Global therapeutic responses were analyzed by the Wilcoxon rank-sum test, and the proportion of subjects with a rating of "improved" or "marked improvement" was calculated and then analyzed using Fisher's exact test $(P \leq 0.05)$.

\section{Results}

\section{Patient characteristics and disposition}

A total of 157 subjects were randomized to receive either BBOS $1.5 \%(n=78)$ or placebo $(n=79)$ across the two Phase III CAC studies and comprised the integrated intent-to-treat population. All subjects were diagnosed with AC, while AR was self-reported in $79.7 \%$ of subjects. A total of 245 subjects with comorbid $\mathrm{AC}$ and nasal allergy symptoms were randomized to receive either BBOS $1.5 \%(n=123)$ or placebo $(n=122)$ in the environmental allergen study and comprised the intentto-treat population. Subject demographics were well balanced between the BBOS 1.5\%- and placebo-treatment arms in both the pooled CAC study population and environmental allergen study population. ${ }^{19,21}$

\section{Efficacy: integrated Phase III CAC studies}

Mean (SD) integrated scores for the nasal symptoms of rhinorrhea, nasal congestion, nasal pruritus, and NOCS 10 minutes following a $\mathrm{CAC}$ at the baseline visit (visit 1) were indicative of mild severity of these symptoms at baseline (Table 1). Mean (SD) scores and treatment differences in mean scores (placebo - active) for the nasal symptoms at 15 minutes, 8 hours, and 16 hours (study visits 3-5) following treatment instillation are shown in Table 1. Mean rhinorrhea scores for the 15-minute (onset of action), 8-hour, and 16-hour (duration of action) CACs in BBOS $1.5 \%$-treated eyes were significantly lower than those for placebo ( $P \leq 0.0007$ for most time points). However, mean rhinorrhea treatment differences were $<1$ unit for all but the 15-minute post-CAC time point for the CAC conducted 8 hours after test-agent instillation, indicating that clinical significance (defined as $\geq 1$-unit improvement at all post-CAC time points) was not reached.

Mean scores for nasal congestion and nasal pruritus using integrated CAC data were significantly lower for BBOS $1.5 \%$ vs placebo at the 15 -minute (all $P \leq 0.0071$ ) and 8-hour CAC (all $P \leq 0.004$ ), but not at the 16-hour CAC for either nasal congestion or nasal pruritus. Mean NOCS scores for BBOS were statistically significantly lower relative to placebo at all time points at all visits $(P \leq 0.0122)$.

\section{Efficacy: Phase IV environmental allergen study}

Baseline mean values and mean change from baseline over 2 weeks of ocular treatment with BBOS or placebo for iINSS, rINSS, iTNSS, and rTNSS values in the environmental 
Table I Mean rhinorrhea, nasal congestion, nasal pruritus, and nasal ocular symptom scores post-CAC conducted at I5 minutes, 8 hours, and 16 hours after dosing

\begin{tabular}{|c|c|c|c|c|c|c|c|c|c|}
\hline \multicolumn{2}{|c|}{ Time post-CAC ${ }^{a}$} & \multicolumn{2}{|l|}{ Rhinorrhea } & \multicolumn{2}{|c|}{ Nasal congestion } & \multicolumn{2}{|c|}{ Nasal pruritus } & \multicolumn{2}{|l|}{$\underline{\text { NOCS }^{b}}$} \\
\hline & & $\begin{array}{l}\text { Placebo } \\
(n=79)\end{array}$ & $\begin{array}{l}\text { BBOS I.5\% } \\
(n=78)\end{array}$ & $\begin{array}{l}\begin{array}{l}\text { Placebo } \\
(n=79)\end{array} \\
\end{array}$ & $\begin{array}{l}\text { BBOS I.5\% } \\
(n=78)\end{array}$ & $\begin{array}{l}\text { Placebo } \\
(n=79)\end{array}$ & $\begin{array}{l}\text { BBOS I.5\% } \\
(n=78)\end{array}$ & $\begin{array}{l}\text { Placebo } \\
(n=79)\end{array}$ & $\begin{array}{l}\text { BBOS I.5\% } \\
(n=78)\end{array}$ \\
\hline \multicolumn{10}{|c|}{ Screening visit I } \\
\hline Baseline & Mean (SD) & $0.09(0.29)$ & $0.12(0.32)$ & $0.14(0.45)$ & $0.21(0.52)$ & $0.03(0.16)$ & $0.01(0.11)$ & $0.27(0.69)$ & $0.35(0.72)$ \\
\hline 10 minutes & Mean (SD) & $1.82(1.26)$ & $1.58(1.10)$ & $1.46(1.35)$ & $1.38(1.10)$ & $1.15(1.36)$ & $0.82(1.03)$ & $5.38(4.35)$ & $4.46(2.83)$ \\
\hline \multicolumn{10}{|c|}{ I5 minutes (onset of action) } \\
\hline \multirow[t]{2}{*}{7 minutes } & Mean (SD) & $0.94(1.017)$ & $0.28(0.682)$ & $0.72(0.973)$ & $0.31(0.726)$ & $0.52(0.8 \mid 4)$ & $0.18(0.528)$ & $2.63(2.905)$ & $0.95(1.765)$ \\
\hline & $\begin{array}{l}\text { Difference } \\
\text { (P-value) }\end{array}$ & \multicolumn{2}{|c|}{$0.7(<0.000$ I*) } & \multicolumn{2}{|c|}{$0.4(0.003 *)$} & \multicolumn{2}{|c|}{$0.3(0.0023 *)$} & \multicolumn{2}{|c|}{$\mathrm{I} .7(<0.0003 *)$} \\
\hline \multirow[t]{2}{*}{15 minutes } & Mean (SD) & $1.06(1.078)$ & $0.38(0.793)$ & $0.86(I .07 I)$ & $0.35(0.77)$ & $0.66(0.846)$ & $0.19(0.604)$ & $3.3(3.236)$ & $1.33(2.062)$ \\
\hline & $\begin{array}{l}\text { Difference } \\
\text { (P-value) }\end{array}$ & \multicolumn{2}{|c|}{$0.7\left(<0.000 I^{*}\right)$} & \multicolumn{2}{|c|}{$0.5\left(0.0007^{*}\right)$} & \multicolumn{2}{|c|}{$0.5(0.000 \mathrm{I} *)$} & \multicolumn{2}{|c|}{$2.0(<0.0002 *)$} \\
\hline \multirow[t]{2}{*}{20 minutes } & Mean (SD) & $0.81(0.935)$ & $0.35(0.735)$ & $0.87(1.017)$ & $0.37(0.74)$ & $0.52(0.86)$ & $0.21(0.543)$ & $2.94(3.18)$ & $1.31(1.995)$ \\
\hline & $\begin{array}{l}\text { Difference } \\
(P \text {-value })\end{array}$ & \multicolumn{2}{|c|}{$0.5\left(0.0007^{*}\right)$} & \multicolumn{2}{|c|}{$0.5(0.0006 *)$} & \multicolumn{2}{|c|}{$0.3(0.007 \mid *)$} & \multicolumn{2}{|c|}{ I.6 $(0.0002 *)$} \\
\hline \multicolumn{10}{|c|}{8 hours (duration of action) } \\
\hline \multirow[t]{2}{*}{7 minutes } & Mean (SD) & $0.91(1.052)$ & $0.23(0.601)$ & $0.72(0.973)$ & $0.27(0.638)$ & $0.53(0.83)$ & $0.13(0.466)$ & $2.61(2.866)$ & $0.73(1.535)$ \\
\hline & $\begin{array}{l}\text { Difference } \\
\text { (P-value) }\end{array}$ & \multicolumn{2}{|c|}{$0.7\left(<0.000 I^{*}\right)$} & \multicolumn{2}{|c|}{$0.5(0.0007 *)$} & \multicolumn{2}{|c|}{$0.4\left(0.0002^{*}\right)$} & \multicolumn{2}{|c|}{$1.9\left(<0.0003^{*}\right)$} \\
\hline \multirow[t]{2}{*}{15 minutes } & Mean (SD) & $1.33(1.217)$ & $0.24(0.563)$ & $0.97(1.097)$ & $0.40(0.762)$ & $0.75(1.056)$ & $0.21(0.589)$ & $3.95(3.655)$ & I.I (I.945) \\
\hline & $\begin{array}{l}\text { Difference } \\
\text { (P-value) }\end{array}$ & \multicolumn{2}{|c|}{$I . I(<0.0001 *)$} & \multicolumn{2}{|c|}{$0.6(0.0002 *)$} & $0.5(C$ & $\left..000 I^{*}\right)$ & $2.9(<$ & $0002 *)$ \\
\hline 20 minutes & Mean (SD) & $1.05(1.131)$ & $0.31(0.588)$ & $0.95(1.097)$ & $0.40(0.795)$ & $0.67(1.059)$ & $0.26(0.673)$ & $3.46(3.658)$ & $1.32(2.14 I)$ \\
\hline & $\begin{array}{l}\text { Difference } \\
\text { (P-value) }\end{array}$ & $0.7(<$ & $\left.000 I^{*}\right)$ & $0.6(C$ & $.0004 *)$ & 0.4( & $.004 *)$ & $2.1(<$ & $0001 *)$ \\
\hline 16 hours $(d$ & uration of a & ction) & & & & & & & \\
\hline 7 minutes & Mean (SD) & $1.00(1.098)$ & $0.58(0.83)$ & $0.8 \mathrm{I}(0.962)$ & 0.5 I (0.785) & $0.36(0.683)$ & $0.67(1.009)$ & $2.89(3.084)$ & $1.76(2.084)$ \\
\hline & $\begin{array}{l}\text { Difference } \\
\text { (P-value) }\end{array}$ & 0.4 & 0072) & 0.3 & .0356) & 0.3 & .0249) & I.I & $120 *)$ \\
\hline 15 minutes & Mean (SD) & 1.30 (1.191) & $0.60(0.827)$ & $1.00(1.086)$ & $0.69(0.944)$ & $0.38(0.743)$ & $0.8(1.005)$ & $3.97(3.826)$ & $2.22(2.567)$ \\
\hline & $\begin{array}{l}\text { Difference } \\
\text { (P-value) }\end{array}$ & 0.7 & $\left.000 I^{*}\right)$ & 0.3 & $.0601)$ & 0.4 & $. .004 *)$ & 1.8 & $\left.027^{*}\right)$ \\
\hline 20 minutes & Mean (SD) & $1.13(1.202)$ & $0.64(0.897)$ & $0.94(1.066)$ & $0.67(0.949)$ & $0.37(0.79 I)$ & $0.73(I .07 I)$ & $3.57(3.865)$ & $2.22(2.705)$ \\
\hline & $\begin{array}{l}\text { Difference } \\
\text { (P-value) }\end{array}$ & 0.5( & $\left.047^{*}\right)$ & 0.3( & $.0958)$ & 0.4( & $.0172)$ & $1.4(0$ & I22*) \\
\hline
\end{tabular}

Notes: aCACs administered at 8 and 16 hours (duration of action) or 15 minutes (onset of action) after treatment instillation; bsum of four scores - three nasal symptoms (rhinorrhea, nasal congestion, and nasal pruritus) and ear or palate pruritus - each scored on a scale of $0-4$; $* P \leq 0.0125$ for 15 -minute $C A C$ and $P \leq 0.00625$ for 8 -hour and 16-hour CAC, except NOCS ( $P \leq 0.05)$. P-values calculated using two-sample $t$-tests comparing BBOS I.5\% to placebo.

Abbreviations: CAC, conjunctival allergen challenge; BBOS, bepotastine besilate ophthalmic solution; NOCS, nonocular composite-symptom score.

allergen study are shown in Table 2. All mean INSS values were mild/moderate in severity at baseline. The mean decrease from baseline scores over the 2-week treatment period was significantly greater with BBOS $1.5 \%$ compared to placebo for reflective nasal pruritus $(P=0.037)$, reflective sneezing $(P=0.010)$, and instantaneous nasal pruritus ( $P=0.018$, Table 2). However, there was no significant difference in mean change from baseline between BBOS $1.5 \%$ and placebo for instantaneous sneezing, instantaneous/ reflective rhinorrhea, or nasal congestion. The mean change from baseline in rTNSS and iTNSS values was numerically greater for BBOS $1.5 \%$ compared with placebo, but was not significant (both $P=0.125$, Table 2).
Analysis of mean change from baseline for nasal symptoms at individual days and times revealed significant differences in favor of BBOS $1.5 \%$ vs placebo at multiple day and time points. BBOS $1.5 \%$ had the greatest effect on reflective sneezing scores, for which a statistically significant difference was seen in almost half the observation days and times (Figure 3). A significant decrease was also observed for individual symptoms (reflective nasal pruritus at six time points, instantaneous nasal pruritus at five time points, instantaneous sneezing at nine time points; all $P \leq 0.05$ ) and for nasal symptoms overall (rTNSS at three time points, iTNSS at two time points; both $P \leq 0.05$ ).

Exploratory analyses revealed that the median number of days to improvement was significantly shorter for BBOS 
Table 2 Mean change from baseline for twice-daily averaged nasal symptom scores over the treatment period (ITT population)

\begin{tabular}{|c|c|c|c|c|c|}
\hline \multirow[t]{2}{*}{ Nasal symptom ${ }^{a}$} & \multicolumn{2}{|c|}{ Baseline mean (SD) score } & \multicolumn{2}{|c|}{ Mean (SD) change from baseline } & \multirow[t]{2}{*}{$P$-value } \\
\hline & $\begin{array}{l}\text { Placebo } \\
(n=122)\end{array}$ & $\begin{array}{l}\text { BBOS I.5\% } \\
(n=123)\end{array}$ & $\begin{array}{l}\text { Placebo } \\
(n=122)\end{array}$ & $\begin{array}{l}\text { BBOS I.5\% } \\
(n=123)\end{array}$ & \\
\hline \multicolumn{6}{|l|}{ Reflective $^{b}$} \\
\hline Nasal pruritus & $2.34(0.62)$ & $2.44(0.59)$ & $-0.49(0.55)$ & $-0.67(0.60)$ & $0.037^{*}$ \\
\hline Sneezing & $1.92(0.79)$ & $1.98(0.77)$ & $-0.40(0.61)$ & $0.63(0.72)$ & $0.010^{*}$ \\
\hline Rhinorrhea $^{d}$ & $2.31(0.59)$ & $2.35(0.55)$ & $-0.40(0.56)$ & $-0.38(0.58)$ & 0.545 \\
\hline Congestion $^{d}$ & $2.50(0.53)$ & $2.57(0.53)$ & $-0.41(0.55)$ & $-0.46(0.57)$ & 0.772 \\
\hline rTNSS & $9.06(2.03)$ & $9.28(1.85)$ & $-1.68(1.93)$ & $-2.14(2.11)$ & 0.125 \\
\hline \multicolumn{6}{|l|}{ Instantaneous $^{c}$} \\
\hline Nasal pruritus & $2.20(0.65)$ & $2.32(0.66)$ & $-0.44(0.56)$ & $-0.64(0.62)$ & $0.018^{*}$ \\
\hline Sneezing & $1.56(0.90)$ & $1.61(0.89)$ & $-0.40(0.6 \mathrm{I})$ & $-0.52(0.68)$ & 0.142 \\
\hline Rhinorrhea $^{d}$ & $2.18(0.64)$ & $2.18(0.60)$ & $-0.38(0.55)$ & $-0.34(0.56)$ & 0.619 \\
\hline Congestion $^{d}$ & $2.44(0.54)$ & $2.48(0.57)$ & $-0.38(0.52)$ & $-0.44(0.52)$ & 0.527 \\
\hline iTNSS & $8.33(2.23)$ & $8.54(2.04)$ & $-1.53(1.95)$ & $-1.95(1.98)$ & 0.125 \\
\hline
\end{tabular}

Notes: Individual nasal symptoms were measured on a 0-3 scale; iTNSS and rTNSS were the sum of the four individual symptom scores. ${ }^{\circ}$ Denotes the 12 -hour period since last instillation of test agent. 'Denotes the 15-minute period prior to instillation of test agent. ${ }^{~}$ Scores for both placebo $(n=107)$ and BBOS I.5\% ( $\left.n=109\right)$ were for the per patient population. $* P \leq 0.05$ (analysis of covariance).

Abbreviations: ITT, intent to treat; BBOS, bepotastine besilate ophthalmic solution; iTNSS, instantaneous total nasal symptom score; rTNSS, reflective TNSS.

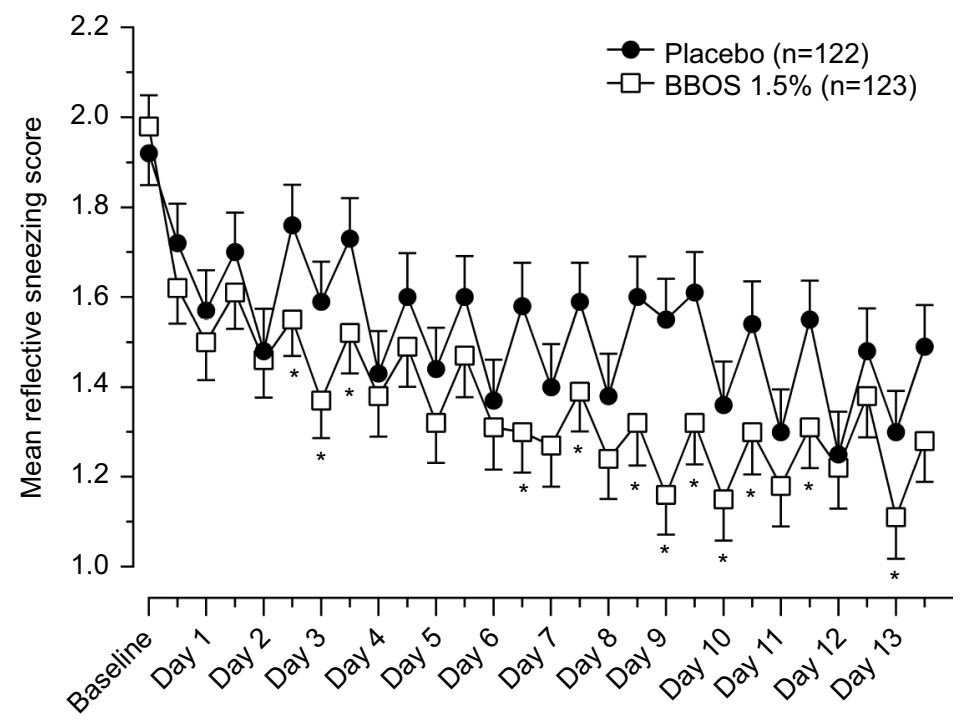

Figure 3 Mean reflective sneezing scores by day and time (ITT population).

Notes: Reflective assessment of sneezing was recorded on a 4-point scale twice daily (morning and evening) during baseline assessment and the 2-week treatment period. Baseline value represents averaged responses of the last seven predose sneezing assessments collected at visit 2 (day 0 ) and twice daily during the 7-day screening period (ie, during the last 3 days of the screening period). $* P \leq 0.05$ vs placebo (analysis of covariance)

Abbreviations: ITT, intent to treat; BBOS, bepotastine besilate ophthalmic solution.

$1.5 \%$ vs placebo for rTNSS, iTNSS, reflective nasal pruritus, and instantaneous nasal pruritus (Table 3 ). Median number of days to improvement was lower with BBOS $1.5 \%$ vs placebo for reflective and instantaneous sneezing, but the difference was not significant (Table 3). Nasal congestion and rhinorrhea were not analyzed by day and time, since there was no significant difference between BBOS $1.5 \%$ and placebo in change from baseline over the 2-week treatment period.

Global therapeutic response analyses are shown in Table 4. The proportion of subjects who self-reported an overall improvement in nasal symptoms for the environmental trial was numerically greater in the BBOS $1.5 \%$-treatment group relative to the placebo group. Based on investigator evaluations, there was a greater difference between BBOS $1.5 \%$ and placebo treatments, with a statistically significant improvement in therapeutic response with BBOS $1.5 \%$ treatment compared to placebo $(P=0.006)$ and a significantly greater proportion of BBOS $1.5 \%$ subjects that were rated by investigators as improved or markedly improved $(P \leq 0.028)$. 
Table 3 Median days to improvement of nasal symptoms (ITT population)

\begin{tabular}{|c|c|c|c|c|c|}
\hline \multirow[t]{2}{*}{ Nasal symptom } & \multicolumn{2}{|l|}{ Placebo } & \multicolumn{2}{|l|}{ BBOS I.5\% } & \multirow[t]{2}{*}{$P$-value } \\
\hline & Days $(95 \% \mathrm{Cl})^{\mathrm{a}}$ & Subjects (n) & Days $(95 \% \mathrm{Cl})^{\mathrm{a}}$ & Subjects (n) & \\
\hline \multicolumn{6}{|l|}{ Reflective $^{\mathrm{b}}$} \\
\hline Pruritus & NA $(10.0-N A)$ & 115 & $7.0(5.5-9.0)$ & 117 & $0.004^{*}$ \\
\hline Sneezing & $13.3(10.0-\mathrm{NA})$ & 104 & $7.5(5.0-13.0)$ & 107 & 0.055 \\
\hline rTNSS & $3.0(1.5-5.0)$ & 118 & $2.0(1.5-3.0)$ & 122 & $0.031 *$ \\
\hline \multicolumn{6}{|l|}{ Instantaneous $^{c}$} \\
\hline Pruritus & $\mathrm{NA}(\mathrm{I} 3.5-\mathrm{NA})$ & 114 & $7.5(6.0-10.5)$ & 118 & $0.00 I^{*}$ \\
\hline Sneezing & $8.5(5.0-\mathrm{NA})$ & 83 & $7.0(4.5-11.0)$ & 93 & 0.184 \\
\hline iTNSS & $4.0(3.0-6.5)$ & 119 & $2.5(1.5-3.5)$ & 122 & $0.010 *$ \\
\hline
\end{tabular}

Notes: aedian days to improvement was the first time point out of $\geq 3$ consecutive time points for which there was a greater decrease in mean averaged scores for BBOS $1.5 \%$ vs placebo; ${ }^{b}$ 2-hour period since last instillation of test agent; ' 15 -minute period prior to instillation of test agent. NA indicates that median time to response for a treatment group was not achieved by the end of the 14 days of dosing during the treatment period. Data analysis was not performed for rhinorrhea or nasal congestion. $* P \leq 0.05$ (log-rank statistics).

Abbreviations: ITT, intent to treat; BBOS, bepotastine besilate ophthalmic solution; iTNSS, instantaneous total nasal symptom score; rTNSS, reflective TNSS.

Table 4 Global therapeutic response ratings by subjects and investigators (proportions)

\begin{tabular}{|c|c|c|c|}
\hline \multirow[t]{2}{*}{ Endpoint } & \multicolumn{2}{|c|}{$\begin{array}{l}\text { Proportion of subjects (\%) with each global therapeutic } \\
\text { response rating }\end{array}$} & \multirow[b]{2}{*}{$P$-value } \\
\hline & Placebo $(n=122)$ & BBOS $1.5 \%(n=123)$ & \\
\hline \multicolumn{4}{|l|}{ Subject evaluation } \\
\hline No change & 43.4 & 34.1 & 0.183 \\
\hline Slight improvement & 36.9 & & 41.5 \\
\hline Improved & 13.9 & & 22.0 \\
\hline Marked improvement & 5.7 & & 2.4 \\
\hline Improved or marked improvement & 19.7 & 24.4 & $0.44 I$ \\
\hline Any improvement & 56.6 & 65.9 & 0.150 \\
\hline \multicolumn{4}{|l|}{ Investigator evaluation } \\
\hline No change & 48.4 & 34.1 & $0.006 *$ \\
\hline Slight improvement & 37.7 & & 39.0 \\
\hline Improved & 9.8 & & 19.5 \\
\hline Marked improvement & 4.1 & & 7.3 \\
\hline Improved or marked improvement & 13.9 & 26.8 & $0.017^{*}$ \\
\hline Any improvement & 51.6 & 65.9 & $0.028 *$ \\
\hline
\end{tabular}

Notes: ${ }^{a} \mathrm{Global}$ therapeutic response (overall assessment of nasal and ocular symptoms) for the 2-week treatment period was graded by subjects at day 13 and investigators at visit 4 (day 14 \pm 2 ), both on a scale of $0-3$. $* P \leq 0.05$. Differences between $B B O S 1.5 \%$ and placebo for the four response categories across treatment groups were analyzed using a Wilcoxon rank-sum test. Differences between BBOS $1.5 \%$ and placebo for the proportion of subjects with a rating of improved or marked improvement and proportion of subjects with any improvement were based on Fisher's exact test.

Abbreviation: BBOS, bepotastine besilate ophthalmic solution.

\section{Discussion}

We report results from an integrated nonocular symptom data set of two Phase III CAC studies and nasal symptoms observed in a Phase IV environmental allergen study with BBOS $1.5 \%$. Both types of clinical studies were doublemasked and randomized and provided evidence for the use of BBOS $1.5 \%$ in alleviating some nasal symptoms. While the $\mathrm{CAC}$ model is highly reproducible, controlled, and objective, ${ }^{13,17}$ it does not allow for testing in a real-world setting, nor does it provide evidence of clinical efficacy and safety over days or weeks of persistent treatment. ${ }^{19}$ Together, the $\mathrm{CAC}$ and environmental allergen studies provide a more comprehensive evaluation of the effectiveness of BBOS $1.5 \%$ in relieving some nasal symptoms. The Phase III CAC studies demonstrated that BBOS $1.5 \%$ instilled as early as
15 minutes or as long as 16 hours prior to the CAC significantly reduced both rhinorrhea and NOCS. In addition, CAC-induced nasal congestion and pruritus were reduced when the $\mathrm{CAC}$ was administered at either 15 minutes or 8 hours after BBOS 1.5\% instillation. Data from the Phase IV environmental allergen study indicated that BBOS 1.5\% likewise improved some nasal symptoms in a real-world setting where allergens were uncontrolled and ubiquitous. BBOS $1.5 \%$ had the greatest effect on reducing sneezing, with additional benefits for relief of total nasal symptoms and nasal pruritus. In this 2-week trial, overall improvement in ocular and nasal allergic symptoms was evaluated by the investigators, as well as by the patient. Investigators reported significant clinical benefit in subjects based on improvement in overall nasal and ocular end points following BBOS $1.5 \%$ 
treatment; however, the subject-reported trend in overall improvement did not reach significance.

This manuscript expands upon previous reports evaluating the efficacy of BBOS $1.5 \%$ in alleviating nasal symptoms in patients with $\mathrm{AC}$, and the data appear consistent with/ improved over other-second generation ocular antihistamines/ mast-cell stabilizers. In one of the two Phase III CAC trials comprising the integrated data set, significant reductions in nonocular symptoms with BBOS $1.5 \%$ were reported. ${ }^{6}$ Importantly, an observational crossover study comparing patient-perceived relief of nasal pruritus and rhinorrhea in patients with AC accompanied by nasal symptoms treated with BBOS $1.5 \%$ or olopatadine hydrochloride ophthalmic solution $0.2 \%$ reported that almost $70 \%$ of patients preferred BBOS $1.5 \%$ for allergen-symptom relief. ${ }^{20}$ In another report, patients treated with olopatadine hydrochloride $0.2 \%$ solution reported relief from sneezing, nasal pruritus, and rhinorrhea but not nasal congestion in two randomized placebo-controlled environmental allergen studies. ${ }^{23}$ In contrast, while azelastine ophthalmic solution $(0.025 \%, 0.05 \%$, and $0.1 \%)$ significantly decreased ocular itching and redness in a randomized and placebo-controlled study in which subjects were exposed to allergens in an allergen-provocation chamber, it was found to be ineffective in alleviating associated nasal symptoms. ${ }^{24}$

As reported previously, BBOS $1.5 \%$ was shown to be safe and well tolerated when dosed bilaterally for up to 2 weeks. ${ }^{6,11,12,19,21}$ More subjects in the BBOS 1.5\%-treatment group (11.4\%) had an AE considered related to treatment than in the placebo group $(4.2 \%)$ in the two CAC studies. ${ }^{21}$ Similarly, in the Phase IV study, more subjects in the BBOS $1.5 \%$-treatment arm reported AEs $(23.6 \%)$ than in the placebo group $(9.1 \%) .{ }^{19}$ However, AEs in all three trials were mild and transient. The most frequently reported BBOS 1.5\%-related $\mathrm{AE}$ in all studies was abnormal/bitter taste, followed by eye irritation and instillation-site pain. No patient discontinued because of a BBOS 1.5\%-related AE, and no serious AEs were reported in any of the trials. . $^{6,11,12,19,21}$

BBOS $1.5 \%$ has previously been shown to rapidly relieve CAC-induced ocular pruritus 8 hours following dosing, as well as reduce secondary signs of inflammation, such as eyelid swelling, ocular tearing, and ciliary hyperemia. ${ }^{21}$ Many similarities exist between the allergic inflammatory responses in nasal and ocular tissue, with the inflammatory reaction unfolding in a similar manner. Primary allergen challenge to the conjunctiva has been shown to elicit allergic symptoms at the nasal mucosa and vice versa. ${ }^{1,8}$ One mechanism to explain the triggering of nasal symptoms after allergen challenge to the ocular tissues is the drainage of allergens and inflammatory mediators, such as histamine, leukotrienes, and prostaglandins, from the eye directly into the nose through the nasolacrimal duct. ${ }^{7}$ Therefore, it is possible that BBOS $1.5 \%$ applied to the eye could inhibit nasal symptoms by passage of the drug from the eye into the nose, as well as by decreasing the flow of inflammatory mediators into the nose. ${ }^{1}$

Other treatment options for comorbid AC and AR besides topical ophthalmic drops include intranasal corticosteroids/ antihistamines or oral antihistamines, ${ }^{5,25}$ A limited number of studies have determined that intranasal antihistamines reduce ocular allergy symptoms, while numerous studies have shown a benefit of intranasal corticosteroids on ocular AC symptoms. ${ }^{5,25-27}$ This may be due to diminished parasympathetic innervation through the pterygopalatine ganglion, rather than a direct effect on the ocular mucosa. ${ }^{8,28}$ Oral antihistamines are often used to treat symptoms of AC and AR, but these agents may only partially treat ocular symptoms. The oral delivery of histamines also can cause drowsiness, reduced tear volume, and induce signs and symptoms associated with ocular dryness, causing ocular discomfort. ${ }^{28-30}$ Secondgeneration topical antihistamines/mast-cell stabilizers for $\mathrm{AC}$ are considered safer because of concentration in affected ocular tissues and minimal systemic exposure, and this also appears true for BBOS 1.5\%.$^{6,11,12,20,21,31}$ BB has minimal suppressive effects on the central nervous system, because the drug cannot cross the blood-brain barrier. ${ }^{10}$ The effectiveness of topical eyedrops may be hindered by patient compliance and tolerance, ${ }^{28}$ however, the convenient twice-daily dosing of BBOS $1.5 \%$ may encourage patients to remain compliant with the fixed-dose regimen. Moreover, the additional benefit of nasal symptom relief may reduce the number of agents a patient must rely on for symptomatic relief.

In the CAC studies, clinical efficacy ( $>1$-unit difference between BBOS and placebo at most time points post-CAC) was not achieved for the nasal symptoms evaluated. This may reflect limitations of the studies in not directly addressing the question of BBOS $1.5 \%$ efficacy for nasal symptoms associated with AC. The CAC trials had a clinical efficacy threshold of a $\geq 1$-unit difference (at least $25 \%$ ) between active- and vehicle-treatment scores for each of the individual primary end points: ocular itching and hyperemia within a visit. This efficacy criteria has been consistently used by the FDA in evaluating the efficacy of ocular allergy signs and symptoms. Equating this efficacy criteria to a $25 \%$ change from baseline end point for nasal symptoms in AR field studies may or may not be valid.

In addition, although almost $80 \%$ of patients reported nasal symptoms, the patient population for the Phase III 
BBOS $1.5 \%$ trials was not required to exhibit symptoms of AR. Therefore, the magnitude of the efficacy of BBOS $1.5 \%$ in alleviating nasal symptoms was likely underestimated, due to the absence of nasal symptoms in one of every five patients. Also, the CAC was applied to the conjunctiva only, with nasal symptoms being secondary to ocular allergen exposure, and nasal symptoms were mild at baseline. Reporting of nasal symptoms in the CAC and environmental clinical trials of BBOS $1.5 \%$ was subjective, and thus error could have been introduced due to subject tolerance and perception. ${ }^{32}$ Lastly, for all three trials, nasal outcomes were measured as secondary efficacy end points, and thus the studies were not powered statistically to address differences between BBOS $1.5 \%$ and placebo.

To understand fully the impact of BBOS $1.5 \%$ treatment in alleviating comorbid AC and AR symptoms, a rigorously designed nasal allergy trial is required, recruiting patients in whom nasal complaints are the predominant symptom, either by incorporating a nasal allergen challenge methodology or in an environmental allergen study.$^{32}$ Further, a study exploring whether concomitant therapy with ocular BBOS $1.5 \%$ and nasal corticosteroids allows for reduced steroid usage would be of value.

In conclusion, BBOS $1.5 \%$ dosed bilaterally twice daily is a safe and potentially beneficial agent for alleviating nasal symptoms associated with AC. The epidemiologic and pathophysiologic relationship between $\mathrm{AC}$ and $\mathrm{AR}$ may explain the dual ocular and nasal effectiveness of BBOS $1.5 \%$ in these patients, and thus BBOS $1.5 \%$ may be considered a treatment option for patients with AC and comorbid nasal symptoms.

\section{Acknowledgments}

Editorial assistance was provided by Ethis Communications Incorporated (White Plains, NY) and funded by Bausch \& Lomb Incorporated.

\section{Disclosure}

MEC and JIW are employees of Bausch \& Lomb Incorporated. PJG is an employee of Ora. The authors report no other conflicts of interest in this work.

\section{References}

1. Bielory L. Allergic conjunctivitis and the impact of allergic rhinitis. Curr Allergy Asthma Rep. 2010;10(2):122-134.

2. Hopper JL, Jenkins MA, Carlin JB, Giles GG. Increase in the selfreported prevalence of asthma and hay fever in adults over the last generation: a matched parent-offspring study. Aust J Public Health. 1995;19(2):120-124.

3. Blaiss MS. Allergic rhinoconjunctivitis: burden of disease. Allergy Asthma Proc. 2007;28(4):393-397.
4. Singh K, Axelrod S, Bielory L. The epidemiology of ocular and nasal allergy in the United States, 1988-1994. J Allergy Clin Immunol. 2010;126(4):778-783.e6.

5. Wallace DV, Dykewicz MS, Bernstein DI, et al. The diagnosis and management of rhinitis: an updated practice parameter. J Allergy Clin Immunol. 2008;122(2 Suppl):S1-S84.

6. Torkildsen GL, Williams JI, Gow JA, Gomes PJ, Abelson MB, McNamara TR. Bepotastine besilate ophthalmic solution for the relief of nonocular symptoms provoked by conjunctival allergen challenge. Ann Allergy Asthma Immunol. 2010;105(1):57-64.

7. Bielory BP, O'Brien TP, Bielory L. Management of seasonal allergic conjunctivitis: guide to therapy. Acta Ophthalmol. 2012;90(5): 399-407.

8. Hom MM, Bielory L. The anatomical and functional relationship between allergic conjunctivitis and allergic rhinitis. Allergy Rhinol (Providence). 2013;4(3):e110-119.

9. Bielory L, Duttachoudhury S, McMunn A. Bepotastine besilate for the treatment of pruritus. Expert Opin Pharmacother. 2013;14(18):2553-2569.

10. Lyseng-Williamson KA. Oral bepotastine: in allergic disorders. Drugs. 2010;70(12):1579-1591.

11. Macejko TT, Bergmann MT, Williams JI, et al. Multicenter clinical evaluation of bepotastine besilate ophthalmic solutions $1.0 \%$ and $1.5 \%$ to treat allergic conjunctivitis. Am J Ophthalmol. 2010;150(1): $122-127 . e 5$

12. Abelson MB, Torkildsen GL, Williams JI, Gow JA, Gomes PJ, McNamara TR. Time to onset and duration of action of the antihistamine bepotastine besilate ophthalmic solutions $1.0 \%$ and $1.5 \%$ in allergic conjunctivitis: a phase 3 , single-center, prospective, randomized, doublemasked, placebo-controlled, conjunctival allergen challenge assessment in adults and children. Clin Ther. 2009;31(9):1908-1921.

13. Abelson MB. Comparison of the conjunctival allergen challenge model with the environmental model of allergic conjunctivitis. Acta Ophthalmol Scand Suppl. 1999;(228):38-42.

14. Abelson MB, Spitalny L. Combined analysis of two studies using the conjunctival allergen challenge model to evaluate olopatadine hydrochloride, a new ophthalmic antiallergic agent with dual activity. $\mathrm{Am} J$ Ophthalmol. 1998;125(6):797-804.

15. Abelson MB, Turner FD, Amin D. Patanol is effective in the treatment of the signs and symptoms of allergic conjunctivitis and allergic rhinoconjunctivitis. Invest Ophthalmol Vis Sci. 2000;41 Suppl:4922.

16. D'Arienzo PA, Leonardi A, Bensch G. Randomized, double-masked, placebo-controlled comparison of the efficacy of emedastine difumarate $0.05 \%$ ophthalmic solution and ketotifen fumarate $0.025 \%$ ophthalmic solution in the human conjunctival allergen challenge model. Clin Ther. 2002;24(3):409-416.

17. Abelson MB, Loeffler O. Conjunctival allergen challenge: models in the investigation of ocular allergy. Curr Allergy Asthma Rep. 2003;3(4): 363-368.

18. Torkildsen G, Narvekar A, Bergmann M. Efficacy and safety of olopatadine hydrochloride $0.77 \%$ in patients with allergic conjunctivitis using a conjunctival allergen-challenge model. Clin Ophthalmol. 2015;9:1703-1713.

19. Carr WW, Nayak AS, Ratner PH, Gow JA, McNamara TR, Williams JI. Efficacy of bepotastine besilate ophthalmic solution $1.5 \%$ for seasonal allergic conjunctivitis: a randomized, placebo-controlled, natural exposure, clinical trial. Allergy Asthma Proc. 2013;34(3):247-254.

20. McCabe CF, McCabe SE. Comparative efficacy of bepotastine besilate $1.5 \%$ ophthalmic solution versus olopatadine hydrochloride $0.2 \%$ ophthalmic solution evaluated by patient preference. Clin Ophthalmol. 2012;6:1731-1738.

21. Bergmann MT, Williams JI, Gomes PJ. Treatment of allergic conjunctivitis with bepotastine besilate ophthalmic solution $1.5 \%$. Clin Ophthalmol. 2014;8:1495-1505.

22. Abelson MB, Chambers WA, Smith LM. Conjunctival allergen challenge: a clinical approach to studying allergic conjunctivitis. Arch Ophthalmol. 1990;108(1):84-88. 
23. Abelson MB, Gomes PJ, Vogelson CT, et al. Effects of a new formulation of olopatadine ophthalmic solution on nasal symptoms relative to placebo in two studies involving subjects with allergic conjunctivitis or rhinoconjunctivitis. Curr Med Res Opin. 2005;21(5):683-691.

24. Horak F, Berger UE, Menapace R, Toth J, Stübner PU, Marks B. Dosedependent protection by azelastine eye drops against pollen-induced allergic conjunctivitis: a double-blind, placebo-controlled study. Arzneimittelforschung. 1998;48(4):379-384.

25. Hong J, Bielory B, Rosenberg JL, Bielory L. Efficacy of intranasal corticosteroids for the ocular symptoms of allergic rhinitis: a systematic review. Allergy Asthma Proc. 2011;32(1):22-35.

26. Yanez A, Rodrigo GJ. Intranasal corticosteroids versus topical $\mathrm{H}_{1}$ receptor antagonists for 476 the treatment of allergic rhinitis: a systematic review with meta-analysis. Ann Allergy Asthma Immunol. 2002;89(5):479-484.

27. Lightman S, Scadding GK. Should intranasal corticosteroids be used for the treatment of ocular symptoms of allergic rhinoconjunctivitis? A review of their efficacy and safety profile. Int Arch Allergy Immunol. 2012;158(4):317-325.
28. Bielory L, Katelaris CH, Lightman S, Naclerio RM. Treating the ocular component of allergic rhinoconjunctivitis and related eye disorders. MedGenMed. 2007;9(3):35.

29. Ousler GW, Wilcox KA, Gupta G, Abelson MB. An evaluation of the ocular drying effects of 2 systemic antihistamines: loratadine and cetirizine hydrochloride. Ann Allergy Asthma Immunol. 2004;93(5):460-464.

30. Ousler GW 3rd, Workman DA, Torkildsen GL. An open-label, investigator-masked, crossover study of the ocular drying effects of two antihistamines, topical epinastine and systemic loratadine, in adult volunteers with seasonal allergic conjunctivitis. Clin Ther. 2007;29(4):611-616.

31. Williams JI, Gow JA, Klier SM, McCue SL, Salapatek AM, McNamara TR. Non-clinical pharmacology, pharmacokinetics, and safety findings for the antihistamine bepotastine besilate. Curr Med Res Opin. 2010;26(10):2329-2338.

32. Ellis AK, Soliman M, Steacy L, et al. The Allergic Rhinitis Clinical Investigator Collaborative (AR-CIC): nasal allergen challenge protocol optimization for studying AR pathophysiology and evaluating novel therapies. Allergy Asthma Clin Immunol. 2015;11(1):16.
Journal of Asthma and Allergy

\section{Publish your work in this journal}

The Journal of Asthma and Allergy is an international, peer-reviewed open access journal publishing original research, reports, editorials and commentaries on the following topics: Asthma; Pulmonary physiology; Asthma related clinical health; Clinical immunology and the immunological basis of disease; Pharmacological interventions and

\section{Dovepress}

new therapies. This journal is included in PubMed. The manuscript management system is completely online and includes a very quick and fair peer-review system, which is all easy to use. Visit http://www. dovepress.com/testimonials.php to read real quotes from published authors. 